\title{
Pure Cross-Docking as Strategy of Distribution for Courier Services: A Quantitative Study on Perceived Benefits Associated with Inventory Cost
}

\author{
Muhammad Faisal Sultan \\ PhD Scholar KUBS-UoK \& Assistant Professor, KASBIT \\ Shahid Khan \\ Assistant Professor, KASBIT \\ Syed Moazzam Shere \\ Lecturer, KASBIT
}

\begin{abstract}
Cross-Docking is adopted by many companies not only to decrease cost of operations but also to increase level of customer satisfaction and optimize goodwill. Although implementation of the strategy is much complex specially in uncertain courtiers like Pakistan therefore majority of warehouses are opting this strategy in combination with limited warehousing in order to avoid the risk of stock out cost. Therefore there is minimal knowledge available regarding the use and benefits of the strategy. Although the strategy has been used across the world and with CPEC implementation Pakistan might also be included in the list of developed economies and companies coming from abroad require this strategy to work properly. Thus there is a need of study to identify benefits associated with the strategy of pure cross-docking but quantifying numerous benefits through single study is quire impossible. There this study focused specifically upon inventory holding cost as the benefit of cross-docking and after analysis it has been determined that the strategy would not bring impact on the inventory holding cost unless it is impaired with proper communication.
\end{abstract}

Keywords: Pure Cross-Docking, Uncertain Countries, Perceived Benefits of Cross-Docking \& Inventory Cost DOI: $10.7176 /$ IEL/9-4-02

Publication date:May $31^{\text {st }} 2019$

\section{Introduction:}

Since the evolution of Supply Chain Management (SCM) in 1982 (Oliver \& Webber, 1982), the term has gain massive attention in industrial practices as well as in literature (Stadtler, 2005). Although there is a massive change in the practices followed during recent times and cost related issues getting priority in supply chain applications (Khan, Hussainy, Khan, Khan, Sharif \& Tariq, 2017). Therefore direct delivery from factory (Hill, 1999 \& Chen et al., 2001) or via distribution center (Lu \& Posner, 1994 \& Hertz \& Andersson, 2003) is one of the most considerate issues in SCM (Kreng \& Chen, 2008). Supported by Khan et al (2017) that logistic cost is recent center of concern for companies and cross-docking might reduce the cost through direct shipment with minimal focus towards storage.

$\mathrm{Yu}$ and Thapa (2014) also indicated cross-docking as one of the prime strategies for reducing level of inventory and for improving responsiveness in against of customer's requirements. This is achieved through transferring mix of products to same destination without putting away, storing and picking, see figure 1. WalMart is the first company which uses this strategy to gain competitive advantage via direct shipment of goods from suppliers (Stalk \& Lachenauer, 2004).

Cross-Docking has some other advantages as mentioned by Vasiljevic, Stepanovic \& Manojlovic (2013) and Khan et al (2017). Vasiljevic et al (2013) indicated cross-docking resulted in reduction of transportation cost, labor cost, warehousing space etc. Moreover cross-docking also resulted in consolidation and customization of shipment, balancing of demand and supply, improvement of service level and just-in-time deliveries.

Khan et al (2017) indicated that the cross-docking resulted in reduction of lead time, cost, storage space and chances of loss and damage. Moreover through the use of strategy company will also able to improve level of customer satisfaction and get better control over distribution mechanism. Although the strategy is feasible only for large distribution with vehicles taking full truck load (FTL) or less than a truck load (LTL) (Kreng \& Chen, 2008). 


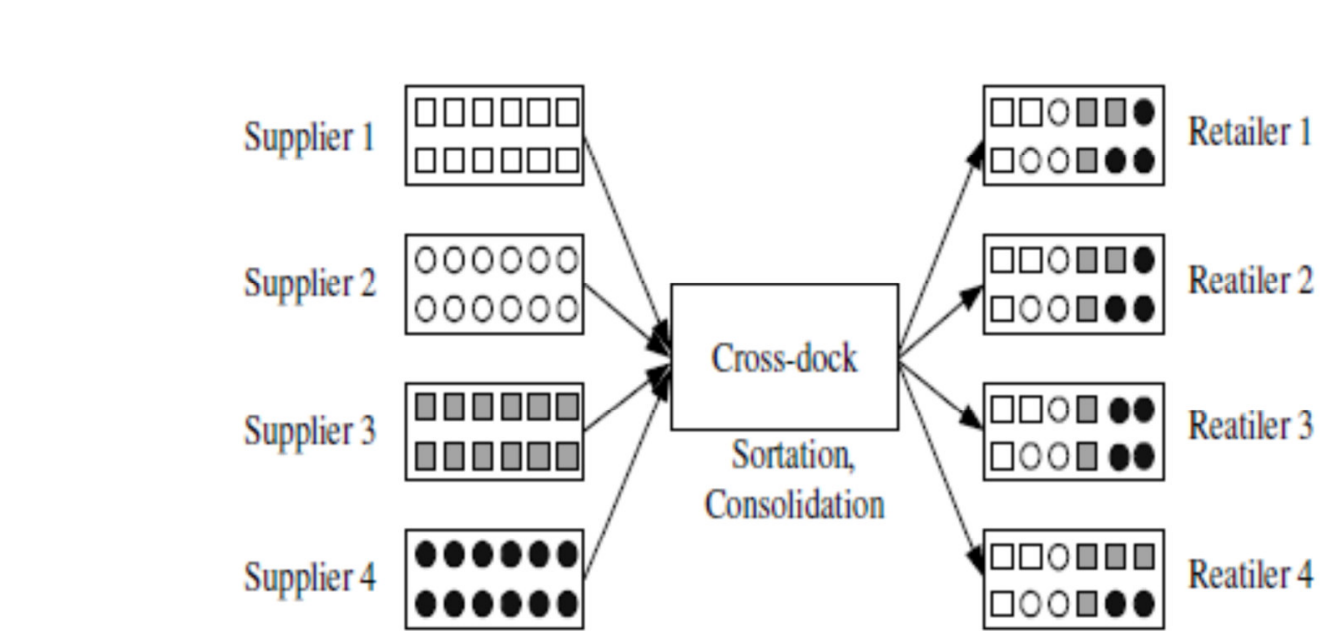

Figure 1: Framework for the strategy of Cross-Docking (Yu \& Thapa, 2014).

\section{Purpose of the Study}

Studies regarding distribution centers and mechanism of distribution are not new in the area of supply chain (Kreng \& Chen, 2008). Though selection of best strategy for distribution is always been a challenge \& studies like (Ertek (2012) indicated that there are three major strategies for distribution i.e. traditional distribution with warehouses and direct shipment and cross-docking. Although Cross-Docking seems to be implemented successfully in many networks (Kreng \& Chen, 2008), therefore awareness regarding strategy enhancement practices followed in Pakistan (Khan et al., 2017).

\section{Problem}

The era of traditional large-scale production comes to end due to continuous change in consumer demands, development of new products and requirement of lesser level of inventory. On the other side suppliers are facing challenges regarding frequent deliveries of small order as market environment demands variety of distribution centers. Therefore cross-docking has been emerged as one of the better strategy for distribution (Kreng \& Chen, 2008). In fact recent focus of studies is towards minimum amount of stocks and maximum coordination between associated parties. Therefore cross-docking is termed as most innovative strategy in the area of supply chain (Guignard Hahn and Zhang, 2013). Though cross-docking cannot be implemented realistically especially in uncertain countries like Pakistan (Khan et al, 2017) as most of the warehouses are not using the strategy of crossdocking (Apte \& Viswanathan, 2000).

Problem became more severe as studies on uncertain countries like Pakistan are minimal in numbers (Khan et al, 2017) with some real world limitations \& assumptions which are ignored while solving real life problems (Sheikholeslam \& Emamian, 2013). Although 3PL and LTL companies are constantly following cross-docking (Terreri, 2001) \& quantitative analysis is required on benefits of cross-docking especially for the logistic companies (Li, He, Sim \& Chen, 2012).

\section{Delimitations}

The selection of couriers services is coherent with Li et al (2012), as well as study of Virsagotis et al (2009) that courier services does not only have high volumes of product but also have relatively lesser fluctuation in demand. Virsagotis et al (2009) posited that courier services have high demand as well as low rate of fluctuations which are linked with the products being sold by retail sector. Wal-Mart is using this strategy abroad to gain competitive advantage (Stalk \& Lachenauer, 2004). Moreover FedEx is also using the facility of cross-docking in other continents. Therefore it is significantly important to understanding regarding the implication of the concept in the scenario of uncertain countries like Pakistan. Moreover study focused only upon inventory holding cost as the perceived benefit of pure cross docking as it is included in the list of benefits indicated by Khan et al (2017) and Vasiljevic et al (2013).

Furthermore Guignard et al (2013) posited that recent focus of supply chain studies is towards minimum amount of stocks \& problems in cross docking are interdependent (Sheikholeslam \& Emamian, 2013) with future studies are required to use combination of problems and limitation (Li et al., 2012).

\section{Theoretical Framework}

In accordance with the points mentioned by Guignard et al (2013) and Sheikholeslam and Emamian (2013) this study use inventory holding cost as dependent variable, proper communication as moderating Variable and Pure 
Cross-docking as independent variable. The reason for using the term pure cross-docking is Khan et al (2017) indicated that pure cross-docking is impractical to implement in uncertain countries like Pakistan although the most of the studies conducted in western scenario are based upon pure cross docking.

Therefore in order to increase awareness regarding the potential benefits of pure cross-docking these types of studies are beneficial to conduct. Especially considering benefits associated with the CPEC for Pakistan studies on benefits of pure cross-docking are mandatory but recent studies in Asia settings are qualitative in nature e.g. Khan et al (2017), Qijun, Zhang, Song and Gui (2009) etc. Hence to avoid much of the conflict and impracticality there is only one moderator and one dependent variable has been selected.

\section{Research Model:}

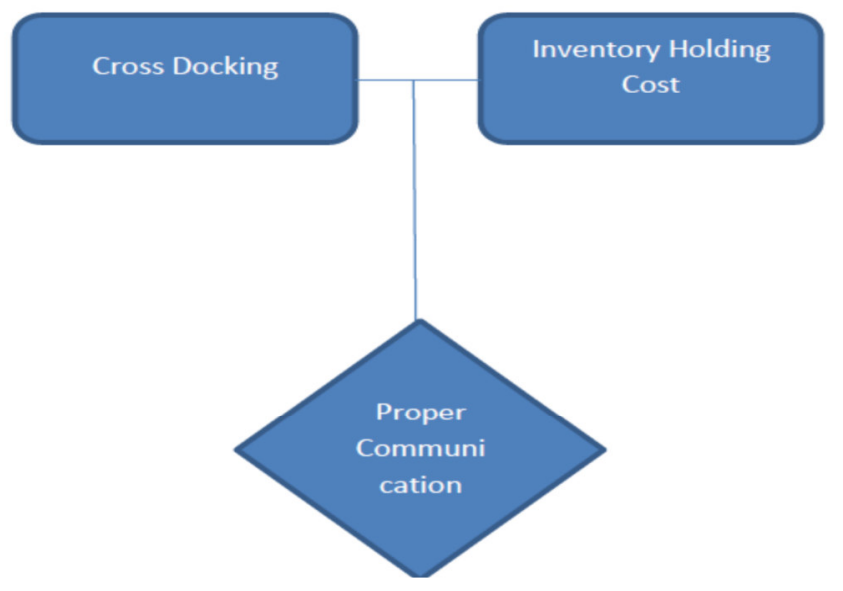

\section{Significance}

The significance of the study has many folds in the field of practicality as well as in academia. This postulate is valid as study will not only indicate the perception regarding perceived benefits for pure cross-docking but also validate the studies like Khan et al (2017) and Apte \& Viswanathan (2000) etc.

Moreover the study will relate the concept of pure cross docking not only with the under developed countries \& also with logistic companies as indicated by $\mathrm{Li}$ et al (2012). Moreover this study will serve as the base for conducting further studies on perceived benefits of cross-docking as well as on the layout design strategies for pure cross-docking.

\section{Research Hypotheses}

H1A: There is a relationship between implementation of pure cross-docking by courier companies and inventory holding cost

H2A: Proper Communication does moderates the relationship between and inventory holding cost and pure cross-docking by courier companies

\section{Literature Review}

There are several companies which are trying to decrease cost of operations and also wishes to increase level of customer satisfaction Study also suggested cross-docking is the strategy which is able to perform both of these functions simultaneously (Gue, 1999). Kreng and Chen (2008) also indicated that cross-docking might resulted in tremendous cost reduction associated with entire supply chain. Study further postulated that increase of order quantity from cross docking's center has direct relation with cost saving. This is actually happen as crossdocking tends to decrease inventory level at warehouse considerably which in turn reduces inventory holding cost (Apte \& Viswanathan, 2000). Absence of warehousing leads to reduction in the space occupied by the warehouse and thus provides opportunity to company for utilizing their real estate assets more effectively. Moreover low cost leads to improvements in corporate cash flows and overall financial performance of the firm. Although cross-docking needs proper communication from entire length of supply chain and especially from distribution center used for the strategy (Vrisagotis, Siassiakos, Panta, Kaimakamis \& Kapetanios, 2009).

These findings are also supported by Khan et al (2017) that cross-docking eliminates the role of warehousing and hence reduces the cost associated with the inventory holding. Study of Khan et al also indicated that during past companies tries to produce large quantities and use warehouses in order to avoid stock out cost but this resulted in congestion of warehouses. Cross-Docking provides them liberty of work without being congested and also increases efficiency in delivery of products. 


\section{Research Design}

Cross-Docking is the strategy of high value and several companies including giants like Wal-Mart, Sears, Asda, Toyota and Mitsubishi as are using the strategy for gaining competitive advantage (Ertek, 2012). Although as mentioned earlier there is lacking of studies on the topic especially in Asia and qualitative nature of available studies e.g. Ertek (2012), Khan et al (2017) and Qijun, Zhang, Song and Gui (2009) making quantitative analysis much complex. Analytical review on Asian context revealed that prior studies can be classified into three categories i.e. implications, benefits \& problems, factors important for cross docking \& review of quantitative approaches for cross-dock assignment. Therefore this study has been done through using the parameters indicated by other studies in order to generate quantitative study on perceived benefits of pure cross-docking.

\section{Sampling Design:}

The technique adopted for the data collection is non-probability sampling as there is severe lacking of measures which can guide data collection approach. Prior studies on this strategy were qualitative and use non-probability sampling i.e. purposive for collection of data e.g., Khan et al (2017) and Qijun Zhang Song and Gui (2009) etc. Therefore the study follows the other method of non-probability sampling i.e. snow-ball sampling in order to ensure availability of most appropriate applicants rather than generalize audience from all the logistic function of courier services. The sample size for this research is 50 respondents in order to predict the potential impact of pure cross-docking on inventory cost.

\section{Questionnaire}

The questionnaire for the study is a hybrid of self-administrative and adaptive approach. The reason for making questionnaire through hybrid technique as there was immense lacking of quantitative studies regarding pure cross docking not only in Asia but all over the world. Thus questionnaire is developed through linking qualitative studies with quantitative studies. Qualitative studies include Ertek (2012), Khan et al (2017) Li et al (2012) and Panousopoulou Papadopoulou and Manthou (2012) in order to develop elements on dependent moderating as well as independent variable. Although quantitative studies are majorly used to design elements associated with dependent variable. Quantitative studies includes Guignard Hahn and Zhang (2014), Gumus and Bookbinder (2004), Kreng and Chen (2008) and Waller Cassady and Ozment (2006) etc. Moreover instrument also includes parameters from latest studies on cross docking e.g. Novaes, Bez, and Adriano (2017)

After that all the elements are transformed to likert scale as the purpose of the questionnaire was to measure attitudes Likert (1932) regarding pure cross-docking. Moreover the transformation to likert scale has also been done to increase its applicability to wider range of constructs (Revilla, Staris and Krosnick, 2014). This optimizes face validity of questionnaire and the values of initial testing (pilot testing). Pilot testing of initial 25 respondents has been done in coherence with as Litwin (1995) that among various types of reliabilities the most considerate one is internal consistency. Moreover Sekaran and Bougie (2010) highlighted that Cronbach Alpha is the best measure to check the internal consistency. Therefore reliability of all the variables has been gauged through taking the reference of Maiyaki and Mohd Mokhtar (2011). Results of Pilot Study might be observed through Table 1. Once values are found appropriate enough to declare the pilot test successful data was gathered for further twenty five respondents through using same sampling method. Results for internal consistency for entire sample (i.e. 50) might be observed through Table 2.

\begin{tabular}{|l|c|c|}
\hline \multicolumn{2}{|c|}{ Reliability Statistics } & \\
\hline & No of Items & Cronbach's Alpha \\
\hline Pure Cross Docking & $\mathbf{5}$ & 0.710 \\
\hline Inventory Holding Cost & $\mathbf{5}$ & 0.709 \\
\hline Proper Communication & $\mathbf{5}$ & 0.682 \\
\hline
\end{tabular}

Table 1 Reliability Values for Pilot Testing

Table 1 highlighted that value of Cronbach Alpha is more than 0.60 for each case. Therefore in accordance with Maiyaki et al (2011) it is legitimate to declare pilot test successful for the designed instrument.

\begin{tabular}{|l|c|c|}
\hline \multicolumn{2}{|c|}{ Reliability Statistics } & \\
\hline & No of Items & Cronbach's Alpha \\
\hline Pure Cross Docking & $\mathbf{5}$ & 0.813 \\
\hline Inventory Holding Cost & $\mathbf{4}$ & 0.751 \\
\hline Proper Communication & $\mathbf{5}$ & 0.722 \\
\hline
\end{tabular}

Table 2 Reliability Analysis for complete sample

Table 2 highlighting that value of Cronbach Alpha is more than 0.7 in every case. Therefore study proceeded towards inferential testing in accordance with Pietersen and Maree (2007) that more than 0.7 of Cronbach's Alphs is optimal.

After descriptive statistics inferential statistics has been employed in order to figure out perceptions of SCM 
managers regarding the impact on pure cross-docking on inventory holding cost. For this purpose Hayes Model has been implemented through SPSS 17.

Reason for preferring Hayes Model over other statistical techniques like SEM is that entire range of variables used in the model are observed variables and the model of study is supplemented with only one moderation (Hayes \& Scharkow, 2013).

Thus in order to avoid any complexities and errors Hayes Model through SPSS has been preferred over AMOS and SMART PLS. Moreover the study is not to develop any new theory \& all the variables are already been evaluated in western context. Although for uncertain countries the concept is bit new but the focus of study is not associated with theory building therefore SMART PLS cannot be incorporated. On the other side smaller sample size restricted the use of AMOS; therefore the use of Hayes Model is legitimate according to statisticians $\&$ technological constraints.

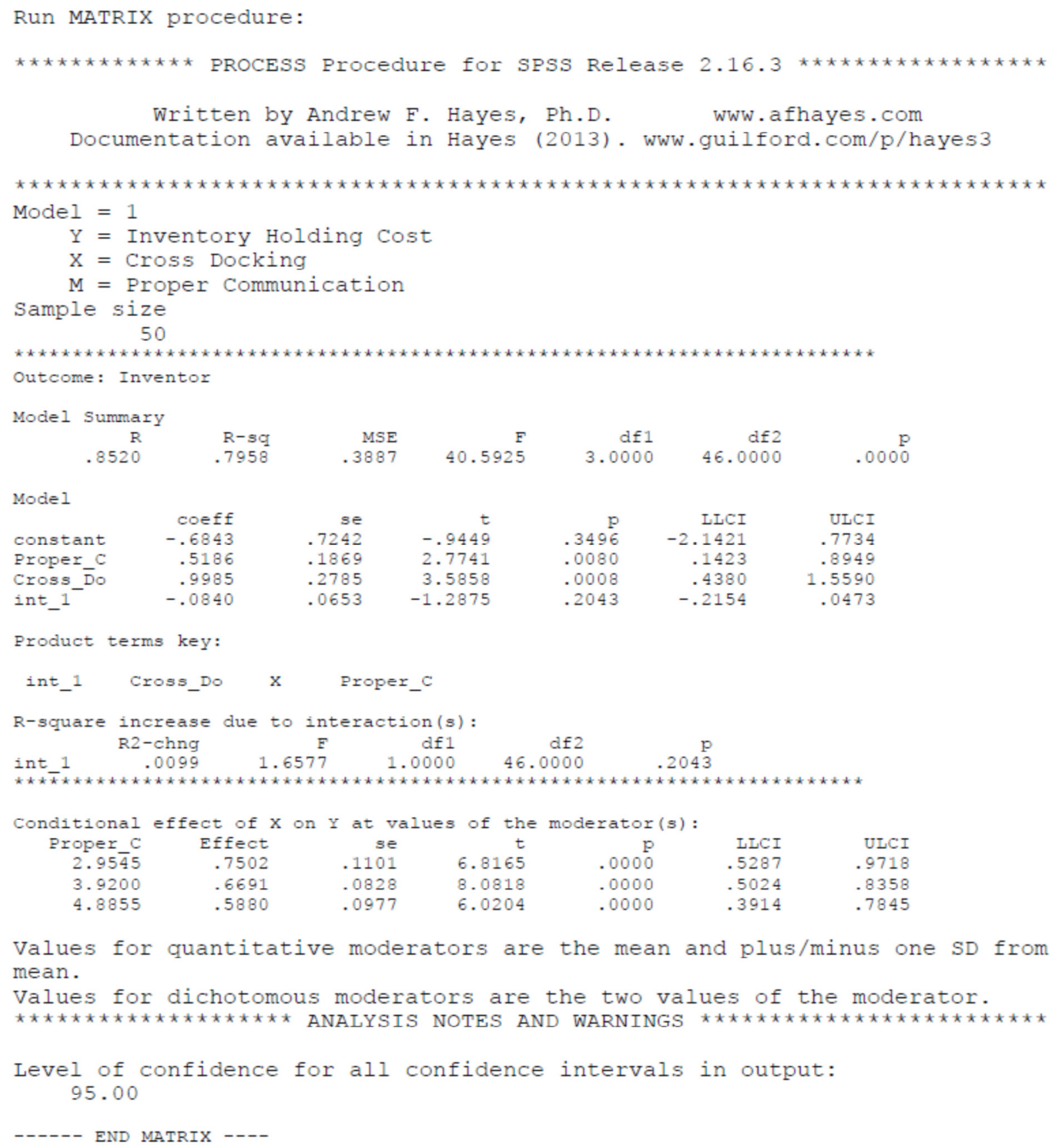

Table 3 Hayes Model: Illustrating the effect of Pure Cross Docking on Inventory Holding Cost

Table 3 indicated that $\mathrm{F}$-value is model is 40.5925 which is large enough to indicate model as fit. Whereas value of $\mathrm{R}$ is more than $85 \%$ and the difference between $\mathrm{R}$ and $\mathrm{R}^{2}$ is less than $6 \%$ while value of $\mathrm{R}^{2}$ is more than $79 \%$. Hence it is legitimate to assume the variation dependent variable is caused majorly by independent variable. 
Table 3 also indicated that pure-cross docking is not perceived as the strategy which can reduce the inventory holding cost. However if the strategy can be coupled with proper communication among associated parties then the strategy might foster better result as highlighted by the table.

\section{Discussion}

After the use of Hayes Model it is has been determined that pure-cross docking is not perceived as the strategy which can decrease inventory handling cost. Though studies of Khan et al (2017) and Vasiljevic et al (2013) posited that decrement in cost of warehousing is one of the leading benefits of cross-docking. Although in uncertain countries like Pakistan application of pure cross-docking is impossible Khan et al (2017), which is aligned with perception of SCM managers of logistic companies.

Proper communication has been included as moderating variable in the research model so to align the propositions of as Apte \& Viswanathan (2000) and Guignard et al (2013). These postulation Apte \& Viswanathan (2000) and Guignard et al (2013) are found to appropriate as through moderation of proper communication, pure cross-docking is effectively decreasing the inventory holding cost.

\section{Area for Future Study}

a) This study is actually conducted to increase concern of intrapreneurs and practioners of supply chain segment that pure cross docking might be a feasible strategy after the launch of CPEC. Therefore the findings of this strategy might be used by any sector having lesser fluctuation in demand and lesser stock out cost, e.g. FMCG and retail sector. Moreover findings of this strategy might also provide to scholars and researchers regarding layout design for pure cross-docking for uncertain country like Pakistan.

b) Further studies might also be conducted through taken some other moderating variables as indicated by Li et al (2012).

\section{References:}

1. Aichlmayr, M. (2001). Never touching the floor. Transportation \& Distribution. 47-52

2. Apte, U. M., \& Viswanathan, S. (2000). Effective cross docking for improving distribution efficiencies. International Journal of Logistics, 3(3), 291-302.

3. Bartholdi, J. J., \& Gue, K. R. (2004). The best shape for a crossdock. Transportation Science, $38(2), 235-$ 244.

4. Belle, J.V., Valckenaers, P., Cattrysse, D. (2012) "Cross-docking: State of the art". Omega, pp. 827-846.

5. Cavana, R. Y., Delahaye, B. L., \& Sekaran, U. (2001). Applied business research: Qualitative and quantitative methods. John Wiley \& Sons Inc

6. Charmaz, K. (2006). Constructing grounded theory: A practical guide through qualitative analysis. Sage.

7. Chen, F., Federgruen, A., and Zheng, Y.S., 2001. Co-ordination mechanisms for a distribution system with one supplier and multiple retailers. Management Science, 47 (5), 693-708

8. Chopra, S., \& Meindl, P. (2016). Supply chain management: Strategy, planning, and operations, ISBN 013-101028-X.

9. Cohen, L., Manion, L., Morrison, K., \& Morrison, R. B. (2007). Research Methods in education , Rout ledge.

10. Ertek, G., (2012) "Crossdocking Insights from a Third Party Logistics Firm in Turkey", in Managing Supply Chains on the Silk Road: Strategy, Performance, and Risk, Eds: Çağrı Haksöz, Sridhar Seshadri and Ananth V. Iyer

11. Galbreth, M. R., Hill, J. A., \& Handley, S. (2008). An investigation of the value of cross - docking for supply chain management. Journal of business logistics, 29(1), 225-239.

12. Gue, K. R. (1999). The effects of trailer scheduling on the layout of freight terminals. Transportation Science, 33(4), 419-428

13. Guignard, M., Hahn, P. M., \& Zhang, H. (2013). Practical cross-docking optimization. TRISTAN VIII. San Pedro de Atacama, Chile, 4-7.

14. Guignard, M., Hahn, P. M., \& Zhang, H. (2013). Practical cross-docking optimization. TRISTAN VIII. San Pedro de Atacama, Chile, 4-7.

15. Guignard, M., Hahn, P., \& Zhang, H. (2014). Dynamic vs. Static Optimization of Cross-docking Operations.

16. Gümüş, M., \& Bookbinder, J. H. (2004). Cross - docking and its implications in location - distribution systems. Journal of Business Logistics, 25(2), 199-228.

17. Hayes, A. F., \& Scharkow, M. (2013). The relative trustworthiness of inferential tests of the indirect effect in statistical mediation analysis: Does method really matter? Psychological Science, 24, 1918-1927

18. Hertz, S. and Alfredsson, M., 2003. Strategic development of third party logistics providers. Industrial Marketing Management, 2 (2), 139-149 
19. Hill, R.M., 1999. The optimal production and shipment policy for the single-vendor single-buyer integrated production- inventory problem. International Journal Production Research, 37 (11), 2463-2475.

20. Johnston, R. B., Mak, H. C., \& Kurnia, S. (2000). The contribution of Internet electronic commerce to advanced supply chain reform-a case study. E-Commerce and V-Business, 232-249.

21. Khan, H., Hussainy, S. K., Khan, K., Khan, E. Sharif, M. \& Tariq, S., (2017), The Implications of CrossDocking in the Manufacturing Sector of Pakistan. International Journal of Supply Chain Management, 6(3), $131-136$

22. Kreng, V. B., \& Chen, F. T. (2008). The benefits of a cross-docking delivery strategy: a supply chain collaboration approach. Production Planning and Control, 19(3), 229-241., doi: $10.1080 / 09537280801916157$

23. Kurina and Johnson (2001) pointed out that cross-docking can be an effective strategy as it reduces the cost but it requires trust, cooperation and proper communication among the supply chain partners. The cost reduced by around 21 percent

24. Li, Z., He, W., Sim, C. H., \& Chen, C. C. (2012). A solution for cross-docking operations planning, scheduling and coordination. Journal of Service Science and Management, 5(02), 111-117

25. Likert, R. (1932). A technique for the measurement of attitudes. Archives of psychology, 22 (140), 55

26. Litwin, M. S. (1995). How to measure survey reliability and validity (Vol. 7). Sage.

27. Lu, L. and Posner, M.E., 1994. Approximation procedures for the one-warehouse multiretailer system. Management Science, 40 (10), 1304-1316

28. Maiyaki, A. A., \& Mohd Mokhtar, S. S. (2011). Determinants of customer behavioural responses: A pilot study. International business research, 4(1), 193-197.

29. McMillan, J. H. and Schumacher, S., (2006), "Research in Education" $6^{\text {th }}$ Ed., Pearson, New York.

30. Morton, R. (1996). Design customer service into your space. Transportation \& Distribution, 37(5), 124-129.

31. Novaes, A. G., Bez, E. T., \& Adriano, D. D. (2017). An Approximate Cost-Integrated Modeling Approach to Cross Dock Design. Pesquisa Operacional, 37(1), 29-66

32. Oliver, R. K., \& Webber, M. D. (1982). Supply-chain management: logistics catches up with strategy. Outlook, 5(1), 42-47.

33. Panousopoulou, P., Papadopoulou, E. M., \& Manthou, V. (2012). Cross-Docking A Successful Method in Warehouses: A Case Study of a 3PL Provider. In 2nd International Conference on Supply Chains.

34. Pietersen, J., \& Maree, K. (2007). Statistical analysis II: Inferential statistics. First steps in research. Pretoria: Van Schaik, 197-213.

35. Popescu, G., Constantin, F., Menda, T. (2010): Efficient transfer of knowledge in agriculture through cooperative structures, Economics of Agriculture, IAE, Belgrade, Special Issue -1, pp. 239-245

36. Qijun, Q., Zhang, Z., Song, X., \& Gui, S. (2009, December). Application research of cross docking logistics in food cold-chain logistics. In 2009 International Conference on Information Management, Innovation Management and Industrial Engineering (Vol. 3, pp. 236-240). IEEE.

37. Ramaa, A., Subramanya, K. N., \& Rangaswamy, T. M. (2012). Impact of warehouse management system in a supply chain. International Journal of Computer

38. Revilla, M. A., Saris, W. E., \& Krosnick, J. A. (2014). Choosing the number of categories in agree-disagree scales. Sociological Methods \& Research, 43(1), 73-97.

39. Richardson, H.L. (2004). Execution at the dock. Logistics Today, 45(4), 31-33

40. Schwind, G. F. (1996). A systems approach to docks and cross docking. Material Handling Engineering, 51(2), 59-62.

41. Scotland, J. (2012). Exploring the Philosophical Underpinnings of Research: Relating Ontology and Epistemology to the Methodology and Methods of the Scientific, Interpretive, and Critical Research Paradigms. English language teaching, 5(9), 9-16

42. Sekaran, U., \& Bougie, R. (2010). Research methods for business: A skill building approach . Chichester: John Willey \& Sons Ltd.

43. Sekaran, U., \& Bougie, R. (2016). Research methods for business: A skill building approach. John Wiley \& Sons Ltd.

44. Shanahan, J. (2004). Cross docking spruces up Urban Outfitters. Logistics Management, 43(1), 65

45. Sheikholeslam, M. N., \& Emamian, S. (2013). Review and Classification of Cross-Docking Concept. International Journal of Learning Management Systems. 4(1), 25-33

46. Shuib, A., \& Fatthi, W. N. A. W. A. (2012). A review on quantitative approaches for dock door assignment in cross-docking. International Journal on Advanced Science, Engineering and Information Technology, 2(5), 370-374.

47. Stadtler, H. (2005). Supply chain management and advanced planning-basics, overview and challenges. European journal of operational research, 163(3), 575-588.

48. Stalk, J.G. and Lachenauer, R., (2004). Hard ball: five killer strategies for trouncing the competition. 
Harvard Business Review, 82 (4), 62-71

49. Sung, C.S. and Song, S.H. (2003). Integrated service network design for a cross-docking supply chain network. Journal of the Operational Research Society, 54, 1283-1295.

50. Terreri, A. (2001). Profiting from Cross Docking. Warehousing Management, 8(8), 29-32.

51. Thapa, G.B., Dhamala, T.N., Pant, S.R., (2011): Cross-Docking Operations for Supply Chain Logistics in JIT Production and Distribution Systems, Journal of the Institute of Engineering, Tribhuvan University, Vol. 8, No. 1, pp. 219-230

52. Ullman, S. (2001). In BG Tabachnick, \& LS Fidell (Eds.), Using multivariate statistics (pp. 653-771 ed., p. 966).

53. Vasiljevic, D., Stepanovic, M., \& Manojlovic, O. (2013). Cross docking implementation in distribution of food products. Economics of Agriculture, 60 (1), 91-111

54. Vrisagotis, V., Siassiakos, K., Panta, M., Kaimakamis, G., \& Kapetanios, G. (2009). The problem of crossdocking analyzed by Markov chain method. The application to a major Greek retailer. supply chain management, 5,6 .

55. Waller, M. A., Cassady, C. R., \& Ozment, J. (2006). Impact of cross-docking on inventory in a decentralized retail supply chain. Transportation Research Part E: Logistics and Transportation Review, 42(5), 359-382

56. Witt, C. E. (1998). Cross docking: Concepts demand choice. Material Handling Engineering, 53(7), 44-49

57. Yang, K. K., Balakrishnan, J., \& Cheng, C. H. (2010). An analysis of factors affecting cross docking operations. Journal of business logistics, 31(1), 121-148.

58. Yu, H., \& Thapa, G. B. (2014). A Cross-Docking Framework for Supply Chain Logistics in Production Scheduling. Journal of Institute of Science and Technology, 19(1), 39-44.

59. Zhengping, L., Malcolm, Y. H. L., Roland, Y. G. L. (2009): Optimal Decision-making on Product Rankins For Cross docking/Warehousing Operations, International Journal of Services Operations and Informatics, Inderscience Publishers, Vol. 4, Issue 4, p. 352-365 